\title{
Возраст вероятной астроблемы Ярва-варака: U-(Th)-Pb SHRIMP II данные для бадделеита и циркона
}

\author{
Каулина Т.В. ${ }^{1,2}$, Лялина Л.М. ${ }^{1,2}$, Нерович Л.И. ${ }^{1}$, Ильченко В.Л. ${ }^{1}$, Кунаккузин Е.Л. ${ }^{1}$, \\ Борисенко Е.С. ${ }^{1}$, Сосновская М.А. ${ }^{2}$ \\ ${ }^{1}$ Геологический институт КНЦ РАН, Anamumbl, kaulina@geoksc.apatity.ru \\ 2 Anатиский филиал МГТУ, Anamumbl, kaulina@geoksc.apatity.ru
}

Аннотация. Проведено локальное SHRIMP II датирование бадделеита и циркона из пижонитавгитовых диоритов расслоенного массива Ярва-варака, расположенного в Мончегорском районе. Ранее на основе геолого-петрологических исследований была предложена импактная модель происхождения массива. Возраст бадделеита, относящегося к раннему парагенезису породы составляет $2498 \pm 6$ млн. лет. Возраст циркона, отражающего кристаллизацию поздней гранофировой составляющей равен $2492 \pm 3$ млн. лет. Полученные данные наряду с геологическими доказательствами импактного происхождения массива Ярва-варака, позволяют утверждать, что на сегодняшний день, астроблема Ярва-варака является самой древней из известных на Фенноскандинавском щите.

Ключевые слова: циркон, бадделеит, импактные структуры, расслоенные интрузии, Мончегорский рудный район.

\section{An age of probable Jarva-varaka astrobleme: U-(Th)-Pb SHRIMP II data for baddeleyite and zircon}

\author{
Kaulina T.V. ${ }^{1,2}$, Lialina L.M. ${ }^{1,2}$, Nerovich L.I. ${ }^{1}$, Il'chenko V.L. ${ }^{1}$, Kunalluzin E.L. ${ }^{1}$, \\ Borisenko E.S. ${ }^{1}$, Sosnovskaya M.A. ${ }^{2}$ \\ ${ }^{1}$ Geological Institute of Kola Science Centre of RAS, Apatity, kaulina@geoksc.apatity.ru \\ ${ }^{2}$ Apatity branch of MSTU, Apatity, kaulina@geoksc.apatity.ru
}

\begin{abstract}
Local SHRIMP II dating of baddeleyite and zircon from pigeonite-augite diorites of the layered Jarva-varaka massif located in the Monchegorsk ore district was carried out. Earlier, an impact origin of the massif was proposed based on geological and petrological studies. An age of baddeleyite related to the early paragenesis of the rock is $2498 \pm 6 \mathrm{Ma}$. An age of zircon, reflecting the crystallization of the late granophyre component, is $2492 \pm 3$ Ma. The obtained data, along with geological evidence of the impact origin of the Jarva-varaka massif, suggest that today, the Jarva-varaka astrobleme is the oldest known on the Fennoscandinavian Shield.
\end{abstract}

Key words: zircon, baddeleyite, impact structures, layered intrusions, Monchegorsk ore district.

\section{Введение}

Массив Ярва-варака расположен в Мончегорском рудном районе и представляет собой расслоенную интрузию мощностью до 2 км (Докучаева, Борисова, 1974; Расслоенные интрузии..., 2004). Исследования последних лет позволяют предполагать импактное происхождение массива Ярва-варака (Нерович и др., 2015; Нерович и др., 2019). Массив сложен норитами, гиперстеновыми диоритами, пижонит-авгитовыми диоритами, кварцевыми диоритами и гранодиоритами. Возраст кварцевых диоритов составляет $2496 \pm 9$ млн. лет (Расслоенные интрузии..., 2004), возраст мафитовых норитов $-2550 \pm 9$ млн. лет (Нерович и др., 2019).

Исследования циркона из мафитовых норитов методом КР-спектроскопии показали, что породы в большом количестве содержат захваченный из вмещающих глиноземистых гнейсов циркон со следами шокового воздействия (Каулина и др., 2017). Полученные данные обусловили необходимость проведения SHRIMP датирования.

В ходе полевых работ 2019 года были отобраны пробы из фельзитовых норитов, пижонитавгитовых диоритов и гранодиоритов массива, а также из вмещающих биотитовых гнейсов. Из всех проб был выделен циркон для изотопного датирования. В пробе биотитовых гнейсов наряду с цир- 
коном выделен монацит. Бадделеит обнаружен только в пробе пижонит-авгитовых диоритов, поэтому датирование было начато именно с этой пробы.

\section{Методика изучения и датирования акцессорных минералов}

Изучение внутреннего строения минералов проводились на электронном сканирующем микроскопе LEO-1450 с энергодисперсионной приставкой XFlash-5010 Bruker Nano GmbH в Геологическом институте КНЦ РАН, г. Апатиты.

Датирование циркона и бадделеита было проведено на масс-спектрометре SHRIMP-II в Центре Изотопных Исследований Всероссийского Геологического Института им. Карпинского (г. Санкт-Петербург). Процедура U-Pb анализов на масс-спектрометре SHRIMP-II для бадделеита подробно описана в работе (Родионов и др., 2009). Зерна бадделеита и циркона были имплантированы в эпоксидную смолу вместе с зернами стандартов бадделеита Phalaborwa и циркона 91500. Поскольку общепринятого концентрационного стандарта для бадделеита на сегодняшний день нет, концентрации ${ }^{238} \mathrm{U}$ и ${ }^{232} \mathrm{Th}$ в измеренных зернах бадделеита оценивались относительно измеренного концентрационного стандарта циркона 91500 (81.2 ppm U). Поскольку бадделеит относится к минералам с пониженным $\mathrm{Th} / \mathrm{U}$ отношением, коррекция на обыкновенный свинец осуществлялась по ${ }^{208} \mathrm{~Pb}$-методу (Родионов и др., 2009 и ссылки там).

\section{Результаты и обсуждение}

Бадделеит в пробе пижонит-авгитовых диоритов представлен мелкими (60-100 мкм) темнокоричневыми зернами. Во всех зернах обнаружены нарастания или врастания циркона, или образование цирконовых кайм на границе с биотитом и другими минералами (рис. 1).

Циркон в пробе пижонит-авгитовых диоритов представлен длиннопризматическими кристаллами с включениями или скелетными кристаллами в сростках с породообразующими минералами: кварцем, полевыми шпатами, биотитом (рис. 2). Такой состав включений и сростков предполагает образование кристаллов циркона совместно с образованием гранофира (Pl+Kfs+Qtz). Скелетный рост указывает на быструю кристаллизацию расплава. Гранофиры часто встречаются в расслоенных комплексах и представляют собой либо производные кристаллизации остаточной магмы, либо результат плавления кислых пород кровли под термальным воздействием основной магмы интрузивов (Налдретт, 2003; Расслоенные интрузии..., 2004).
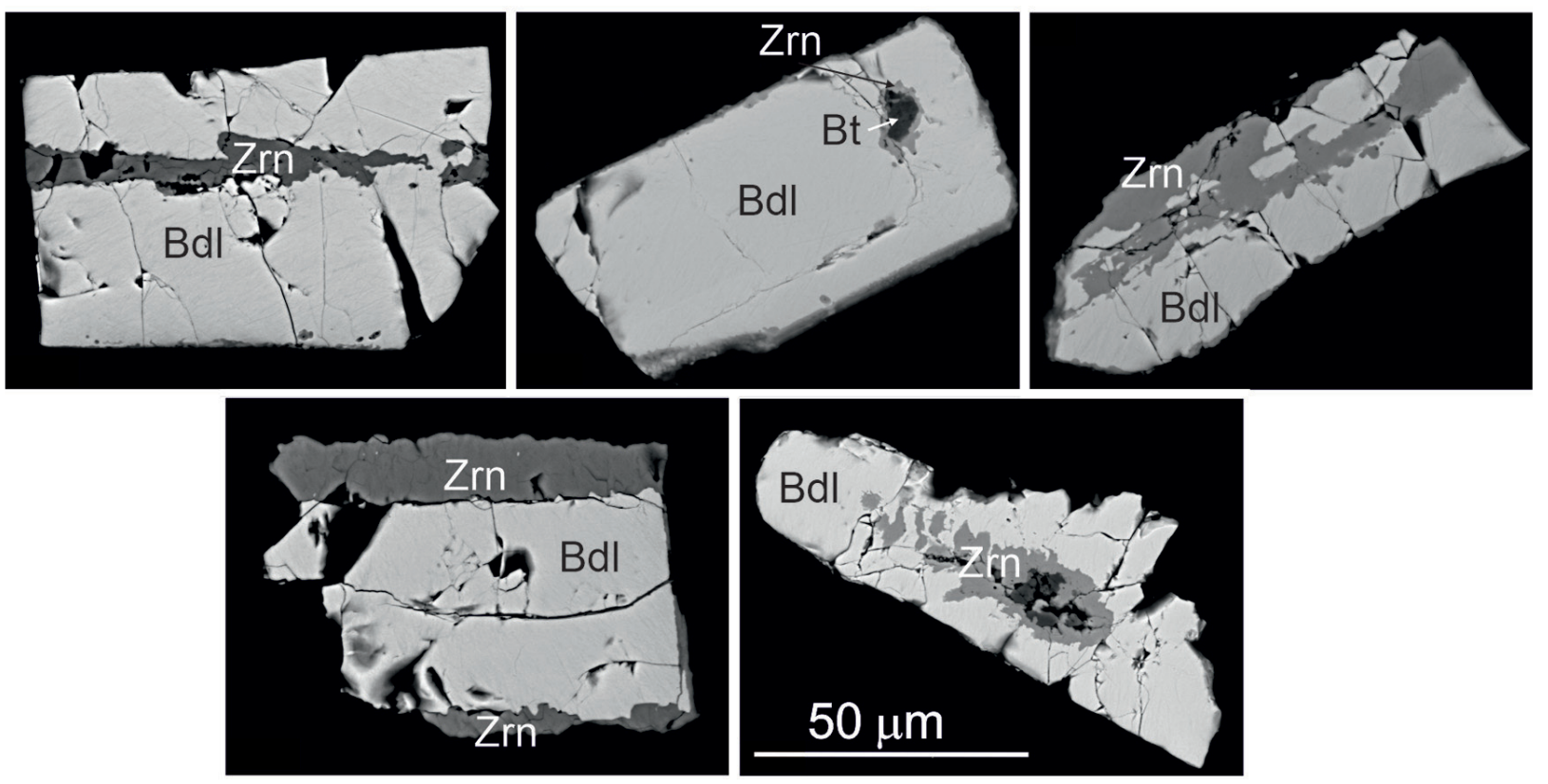

Рис. 1. Микрофотографии кристаллов бадделеита (Bdl) с цирконом (Zrn) из пробы пижонит-авгитовых диоритов. SEM, BSE.

Fig. 1. Images of baddeleyite (Bdl) crystals with zircon ( $\mathrm{Zrn})$ inclusions and rims from pigeonite-augite diorite. SEM, BSE. 

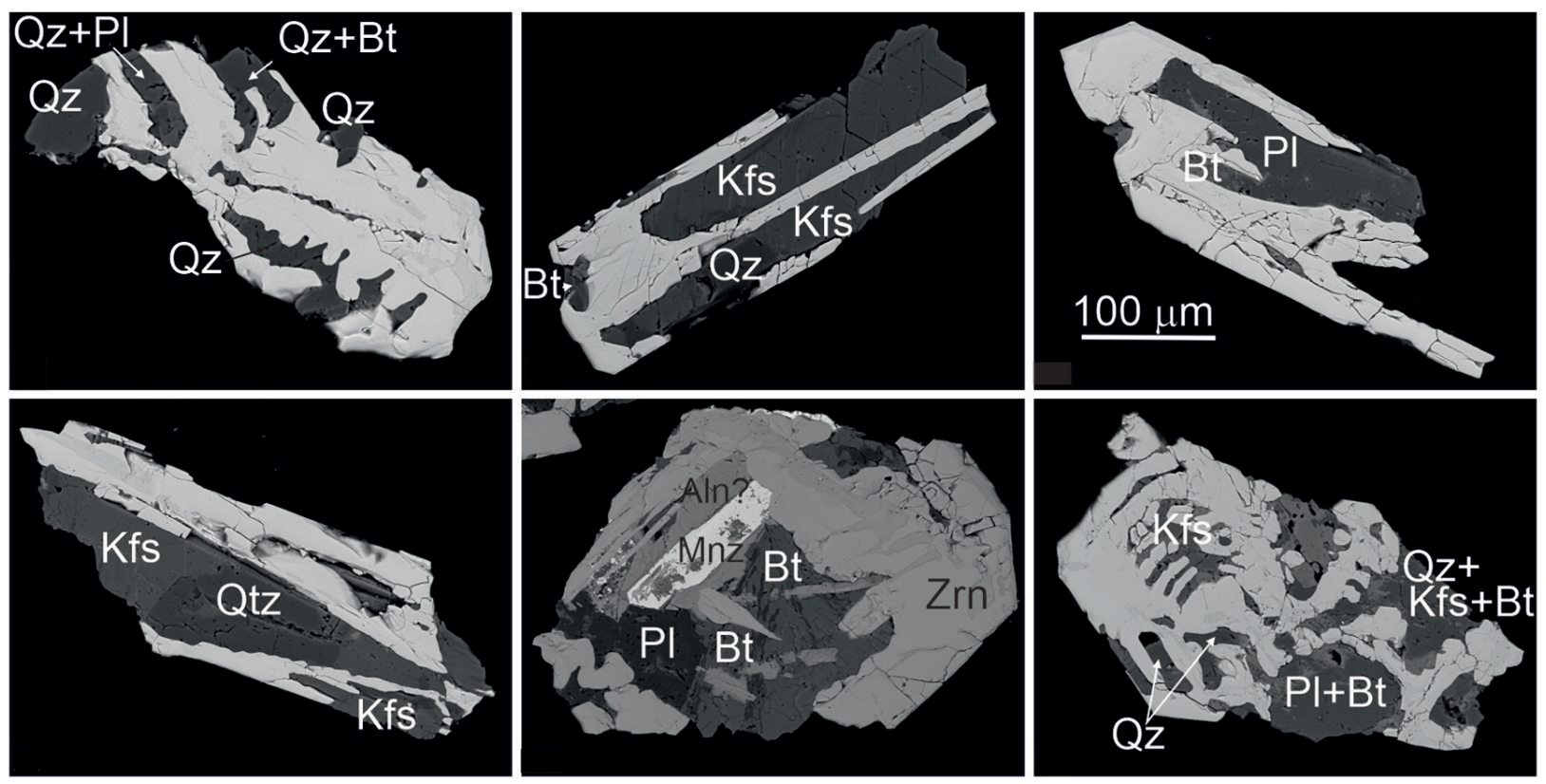

Рис. 2. Микрофотографии циркона из пробы пижонит-авгитовых диоритов. SEM. BSE.

Fig. 2. BSE-images of zircon from pigeonite-augite diorite. SEM, BSE.


Pис. 3. U-(Th)-Pb SHRIMP-II данные для бадделеита (a) и циркона (б) из пробы пижонит-авгитовых диоритов.

Fig. 3. U-(Th)-Pb SHRIMP-II data for baddeleyite (a) and zircon (б) from pigeonite-augite diorite. 
B результате SHRIMP датирования, бадделеит и циркон показали конкордантные возрасты (рис. 3). Бадделеит содержит до 200 ppm урана и очень мало тория (2 ppm). Циркон отличается высоким содержанием урана (1000-1800 ppm) и тория (2500-4100 ppm). Конкордантный возраст бадделеита, определенный по 15 аналитическим точкам, составляет $2502 \pm 11$ млн. лет (рис. 3 a), средний возраст, рассчитанный по отношению ${ }^{207} \mathrm{~Pb} /{ }^{206} \mathrm{~Pb}$ равен $2498 \pm 6$ млн. лет (рис. 3 б). Поскольку, при расчете конкордантного возраста, вероятность результирующей конкордантной точки равна нулю (рис. $3 \mathrm{a}$ ), более надежным является расчет среднего возраста по ${ }^{207} \mathrm{~Pb} /{ }^{206} \mathrm{~Pb}$ отношению (рис. 3 б). Таким образом, за возраст кристаллизации бадделеита принимается значение $2498 \pm 6$ млн. лет. Возраст циркона по верхнему пересечению дискордии по 10 близконкордантным точкам составляет $2492 \pm 3$ млн. лет (рис. 3 в) и совпадает со средним возрастом по отношению ${ }^{207} \mathrm{~Pb} /{ }^{206} \mathrm{~Pb}$.

В пределах ошибки возрасты бадделеита и циркона перекрываются, но учитывая, что биотит развивается по пироксену, который вместе с плагиоклазом № 47 образует ранний парагенезис породы, а ассоциация кварца, калишпата и олигоклаз-андезина № 30 образует более поздний гранофировый парагенезис, можно предположить более раннюю кристаллизацию бадделеита по сравнению с цирконом в узком возрастном интервале.

Полученный возраст $2498 \pm 6$ млн. лет пижонит-авгитовых диоритов массива Ярва-варака полностью совпадает с возрастом кварцевых диоритов массива (2496 9 млн. лет - Расслоенные интрузии..., 2004). Кристаллизация гранофира происходила на последнем этапе застывания массива в $2492 \pm 3$ млн. лет.

\section{Выводы}

В результате датирования бадделеита и циркона определен возраст кристаллизации пород массива Ярва-варака в интервале 2498-2492 млн. лет.

Полученные данные наряду с геологическими доказательствами импактного происхождения массива Ярва-варака, позволяют утверждать, что на сегодняшний день, астроблема Ярва-варака является самой древней из известных на Фенноскандинавском щите.

Работа выполнена в рамках темы НИР № 0226-2019-0052.

\section{Литература}

1. Докучаева В.С., Борисова В.В. К вопросу о геологии и петрографии массива Ярва-Варака, Мончегорский р-н // Региональная геология, металлогения и геофизика. Апатиты. Изд-во: КФ АН СССР. 1974. C. $82-87$.

2. Каулина Т.В., Нерович Л.И., Бочаров В.Н., Лялина Л.М., Ильченко В.Л., Кунаккузин Е.Л., Касаткин И.А. Рамановская спектроскопия импактного циркона из расслоенного массива Ярва-варака (Мончегорский рудный район, Кольский полуостров) // Вестник МГТУ. 2017. Т. 20. № 1/1. С. $72-82$. DOI:10.21443/1560-9278-2017-20-1/1-72-82.

3. Налдретт А.Дж. Магматические сульфидные месторождения медно-никелевых и платинометальных руд. Санкт-Петербург: СПбГУ. 2003. 487 с.

4. Нерович Л.И., Баянова Т.Б., Кунаккузин Е.Л., Базай А.В., Некипелов Д.А. Новые результаты геологопетрографического и геохимического изучения расслоенного массива Ярва-варака, Мончегорский рудный район // Труды Ферсмановской научной сессии ГИ КНЦ РАН. 2015. Т. 12. С. 141-146.

5. Нерович Л.И., Баянова Т.Б., Кунаккузин Е.Л., Елизаров Д.В., Базай А.В. К проблеме генезиса массива Ярва-варака (Мончегорский рудный район) // Труды Ферсмановской научной сессии ГИ КЦН РАН. 2019. № 16. C. 413-417. DOI:10.31241/FNS.2019.16.083

6. Расслоенные интрузии Мончегорского рудного района: петрология, оруденение, изотопия, глубинное строение // Ред. Ф.П. Митрофанов, В.Ф. Смолькин. В 2 частях. Апатиты. Изд-во: КНЦ РАН. 2004. 177 с.

7. Родионов Н.В., Беляцкий Б.В., Антонов А.В., Пресняков С.Л., Сергеев С.А. Уран-свинцовый возраст бадделеита (ионный микрозонд SHRIMP-II) и его использование для датирования карбонатитовых массивов // Доклады Академии Наук. 2009. Т. 428. № 2. С. 244-248. 